\title{
Mutations in genes required for T-cell development: IL7R, CD45, IL2RG, JAK3, RAG1, RAG2, ARTEMIS, and $A D A$ and severe combined immunodeficiency: HuGE review
}

Lisa Kalman, $P h D^{1}$, Mary Lou Lindegren, $M D^{2}$, Lisa Kobrynski, $M D^{3}$, Robert Vogt, PhD ${ }^{1}$, Harry Hannon, $P h D^{1}$, Joelyn Tonkin Howard, MSPH ${ }^{4}$, and Rebecca Buckley, $M D^{5}$

\begin{abstract}
Severe combined immunodeficiency (SCID) is an inherited immune disorder characterized by T-cell lymphopenia (TCLP), a profound lack of cellular (T-cell) and humoral (B-cell) immunity and, in some cases, decreased NK-cell number and function. Affected children develop severe bacterial and viral infections within the first 6 months of life and die before 1 year of age without treatment. Mutations in any of eight known genes: IL2RG, ARTEMIS, RAG1, RAG2, ADA, CD45, JAK3, and IL7R cause SCID. Mutations in unidentified genes may also cause SCID. Populationbased genotype and allelic frequencies of these gene defects have not been measured. Some minimal estimates of SCID prevalence are presented. Currently, hematopoietic stem cell transplants are the standard treatment. In clinical trials, gene therapy has been used to reconstitute immune function in patients with IL2RG and ADA defects. The availability of effective therapies, plus the short asymptomatic period after birth, (when stem-cell transplantation is most effective), make SCID a potentially good candidate for newborn screening. Dried blood spots are currently collected from all infants at birth for newborn metabolic screening. Tests for TCLP on dried blood spots could be developed as a screen for SCID. Because SCID may be unrecognized, with infant deaths from infection attributed to other causes, newborn screening is the only way to ascertain true birth prevalence. Validated tests and pilot population studies are necessary to determine newborn screening's potential for identifying infants with
\end{abstract} SCID. Genet Med 2004:6(1):16-26.

Key Words: severe combined immunodeficiency disorder, IL2RG, RAG1, ADA, JAK3

\section{GENES}

For this review, we chose to examine SCID disorders that are characterized by severe T-cell lymphopenia (TCLP) caused by defects in a known gene. The genes reviewed in this article are IL7R, CD45, IL2RG, JAK3, RAG1, RAG2, ARTEMIS, and ADA. Their mode of inheritance, chromosomal location, and function are listed in Table 1. Figure 1 shows the stage of T-cell and NK-cell development that is blocked by gene mutations that cause SCID. The eight genes examined in this review have multiple mutations that cause SCID. Many of these mutations are unique because they are present in only one case. Population-

\footnotetext{
From the ${ }^{1}$ Centers for Disease Control and Prevention, Newborn Screening Quality Assurance Program, ${ }^{2}$ Office of Genomics and Disease Prevention, Atlanta, Georgia; ${ }^{3}$ Emory University, Atlanta, Georgia; ${ }^{4}$ University of Texas Southwestern Medical Center, Dallas, Texas; ${ }^{5}$ Duke University, Durham, North Carolina.

Lisa Kalman, PhD, Newborn Screening Quality Assurance Program, National Center for Environmental Health, Centers for Disease Control and Prevention, 4770 Buford Highway, NE, Mailstop F-43, Atlanta, GA 30341-3724.

Received: August 4, 2003.

Accepted: October 6, 2003
}

DOI: 10.1097/01.GIM.0000105752.80592.A3 based genotype and allele frequencies of these genes have not been measured.

We used several methods to identify articles relevant to SCID. We searched PubMed for all articles published from 1997 to 2001 that included the following key words: "severe combined immune deficiency," "adenosine deaminase deficiency," and "combined B- and T-cell immunodeficiencies." We obtained additional articles by personally locating information in libraries. These papers were reviewed and presented at a CDC-sponsored conference, "Applying Genetic and Public Health Strategies to Primary Immunodeficiency Diseases," which took place November 8-9, 2001 (see http://www. cdc.gov/genomics/info/conference/PI/PIMeeting.htm). We subsequently did a comprehensive PubMed search (all years covered in the database) for articles about each of the eight genes. We also used several search algorithms to locate genetic and epidemiological data from 1990 to 2003. These algorithms included all genes and gene-related phrases as well as epidemiologic terms. A title search verified that the information in these articles was relevant. We then read the articles' abstracts to determine which articles were relevant for this particular review. We conducted an additional search to identify publications describing registries that collected data about patients 
Table 1

Characteristics of SCID $36,40,101$

\begin{tabular}{|c|c|c|c|c|c|c|c|c|c|}
\hline \multirow[b]{2}{*}{ Gene } & \multirow[b]{2}{*}{ Locus } & \multirow[b]{2}{*}{ Gene product/function } & \multicolumn{3}{|c|}{ Presence of } & \multirow{2}{*}{$\begin{array}{c}\text { Mode of } \\
\text { inheritance }^{a}\end{array}$} & \multirow{2}{*}{$\begin{array}{l}\text { No. unique } \\
\text { mutations } \\
\text { identified }\end{array}$} & \multirow{2}{*}{$\begin{array}{l}\text { OMIM } \\
\text { No. }\end{array}$} & \multirow[b]{2}{*}{ References } \\
\hline & & & T-cell & B-cell & NK-cell & & & & \\
\hline$I L 7 R$ & $5 \mathrm{p} 13$ & $\begin{array}{l}\text { IL7 receptor. Needed for T-cell development. } \\
\text { Activates JAK3 kinase }\end{array}$ & - & + & + & $\mathrm{AR}$ & 5 & 146661 & 2,3 \\
\hline$C D 45$ & $1 q 31-q 32$ & $\begin{array}{l}\text { Protein tyrosine phosphatase. Regulates Src kinases } \\
\text { required for T-cell and B-cell antigen receptor } \\
\text { signal transduction }\end{array}$ & - & + & + & $\mathrm{AR}$ & 3 & 151460 & $5-8$ \\
\hline$I L 2 R G$ & Xq13.1 & $\begin{array}{l}\text { gamma-c chain of IL2, 4, 7, 9, } 15 \text { cytokine } \\
\text { receptors. Needed to activate JAK3 for } \\
\text { intracellular signaling }\end{array}$ & - & + & - & XLR & 169 & 308380 & 9,96 \\
\hline$J A K 3$ & $19 \mathrm{p} 13.1$ & $\begin{array}{l}\text { Tyrosine Kinase. Needed for differentiation of } \\
\text { hematopoietic cells }\end{array}$ & - & + & - & $\mathrm{AR}$ & 27 & 600173 & $14,15,97$ \\
\hline$R A G 1$ & $11 \mathrm{p} 13$ & $\begin{array}{l}\text { DNA recombinase. RAG1/RAG2 mediate DNA } \\
\text { recombination during B-cell and T-cell } \\
\text { development }\end{array}$ & - & - & + & AR & 44 & 179615 & 16,98 \\
\hline RAG2 & $11 \mathrm{p} 13$ & $\begin{array}{l}\text { DNA recombinase. Rag1/Rag2 mediate DNA } \\
\text { recombination during B-cell and T-cell } \\
\text { development }\end{array}$ & - & - & + & AR & 18 & 179616 & 17,99 \\
\hline ARTEMIS & $10 \mathrm{p}$ & $\begin{array}{l}\text { Involved in DNA repair during } \mathrm{V}(\mathrm{D}) \mathrm{J} \\
\text { recombination }\end{array}$ & - & - & + & $\mathrm{AR}$ & 9 & 605988 & $18,19,100$ \\
\hline$A D A$ & $20 q 13.11$ & $\begin{array}{l}\text { Part of the purine salvage and methylation } \\
\text { pathways. Needed for removal of toxic } \\
\text { metabolites (e.g. ATP, S-adenosyl } \\
\text { homocysteine) that inhibit lymphoid cells. }\end{array}$ & - & - & - & $\mathrm{AR}$ & 54 & 102700 & $23-25$ \\
\hline
\end{tabular}

${ }^{a}$ Mode of inheritance: AR, autosomal recessive; XLR, X-linked recessive.

from populations in a defined geographic area because these articles did not appear in a population-based epidemiology search.

\section{Gene variants}

\section{IL7R}

The IL7R gene comprises eight exons spanning 20,738 base pairs. ${ }^{1,2}$ Defects in $I L 7 R$ have been recently implicated in SCID. Few patients with $I L 7 R$ mutations have been studied. A number of mutation sites have been identified, including three nucleotide substitutions that resulted in missense mutations, one nonsense mutation, and one substitution that subsequently resulted in a splice-site mutation. ${ }^{3,4}$ The majority of these mutations are located in exon $4 .^{2,3}$

\section{CD45}

The CD45 gene spans over $120 \mathrm{~kb}$. Mutations in CD45 were identified in three patients with SCID. ${ }^{5-8}$ One patient was homozygous for a six base-pair deletion that removed a tyrosine residue that is essential to protein function. Another patient had one allele with a large deletion in CD45 and a point mutation that disrupted a splice site in the other allele.

\section{IL2RG}

The IL2RG gene comprises eight exons spanning 5447 base pairs. ${ }^{1}$ There are 264 mutations in IL2RG that are known to cause SCID. Of these mutations, 169 have been documented in only one patient. ${ }^{9}$ Types of (unique) mutations in IL2RG vary and include 55 missense mutations, 33 nonsense mutations, 10 insertions, 32 deletions, and 33 splice mutations; types also include complex, large deletions, and mutations that affect RNA processing and translation. Mutations are not evenly distributed throughout the gene. Hotspots for mutation occur at CG dinucleotides at cDNA 690-691 and at cDNA 879. ${ }^{10} \mathrm{An}$ other two mutations are associated with a milder form of SCID. ${ }^{11-13}$

\section{JAK3}

The JAK3 gene is comprises 25 exons spanning 24,029 base pairs. ${ }^{1}$ Twenty-seven unique mutations have been identified in $J A K 3$, occurring in all seven structural domains. ${ }^{14}$ No hotspots have been reported and multiple types of mutations have been identified: 13 missense mutations, 7 nonsense mutations, 3 splice site mutations, 2 deletions, and 1 insertion. ${ }^{14,15}$

\section{RAG1}

The RAG1 gene comprises 2 exons spanning 12,544 base pairs. ${ }^{1}$ Fifty-nine independent mutations in RAG1 are known to cause SCID, 44 of which are unique molecular events. ${ }^{16}$ Most of the mutations were missense (36 independent mutations), 12 were frameshift deletions, 10 were nonsense mutations, and one was a frameshift insertion. 


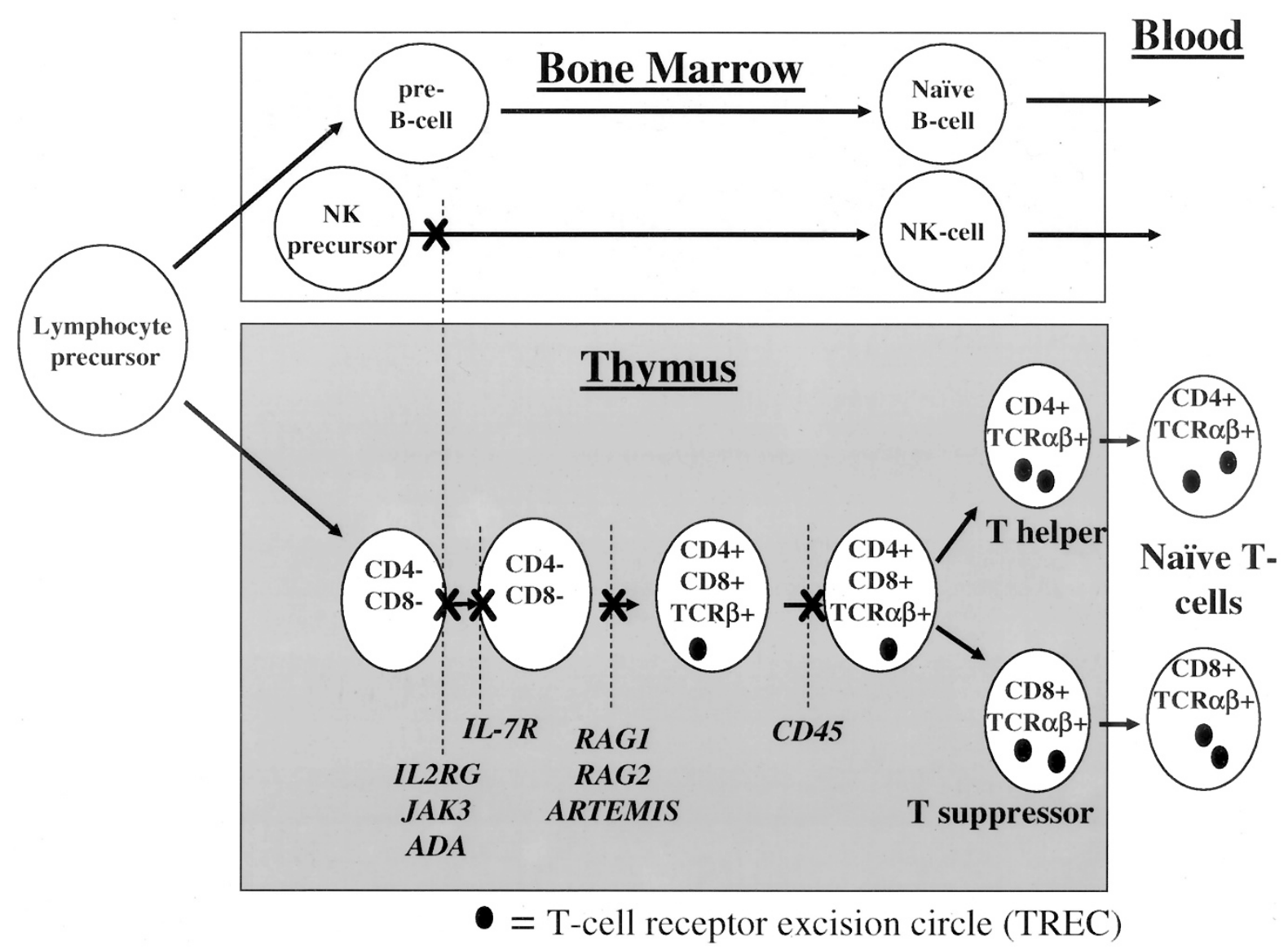

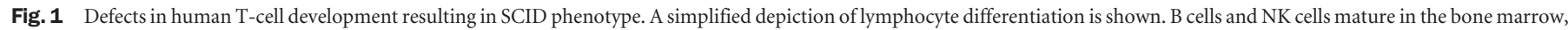

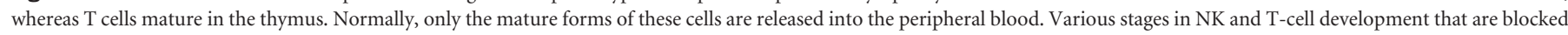

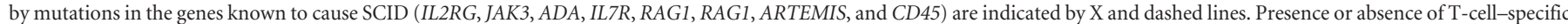
antigenic markers $(\mathrm{CD} 4, \mathrm{CD} 8 \mathrm{TCR} \beta$, and $\mathrm{TCR} \alpha \beta)$ is also indicated. Effects of these mutations on B-cell development is not shown.

\section{RAG2}

The RAG2 gene comprises 2 exons and spans 7092 base pairs. ${ }^{1}$ Of the 21 independent mutations identified in $R A G 2$ that were shown to cause SCID, 18 represent unique molecular events. Fifteen of these mutations were missense, two were nonsense, and one of each of the following: frameshift deletion, inframe deletion, gross deletion, and a frameshift insertion. ${ }^{17}$

\section{ARTEMIS}

The ARTEMIS gene comprises 18 exons and spans 56,665 base pairs. ${ }^{1}$ Mutations in the ARTEMIS gene cause SCID. In Athabascan-speaking Native Americans, a single nonsense mutation in exon 8 of this gene has been identified in 20 of 21 patients with SCID (called SCIDA in this population). One of these patients was heterozygous at this locus; the paternal allele contained the nonsense mutation, and the maternal allele was not expressed. ${ }^{18}$ Haplotype analysis suggests that the high incidence of SCIDA in this population is due to a founder mutation..$^{18}$ In a study of Europeans with SCID caused by mutations in the ARTEMIS gene (RS-SCID), Moshous et al. ${ }^{19}$ have found eight separate mutations in patients from 11 families.
Three of the mutations identified were genomic deletions of two or more exons resulting in a frameshift deletion. One was a one-base deletion that resulted in a frameshift deletion, three were splice-site mutations, and one was a nonsense mutation. No missense mutations were identified.

An epidemiologic study was conducted by Jones et al..$^{20}$ concerning SCID among the Navajo population on the Navajo Reservation, which includes areas of Arizona, New Mexico, and Utah. Death certificate data for 1969 to 1982 indicated that infectious disease-related deaths increased among Navajo children and decreased among non-Navajo children living in the same area. Cases of SCID or probable SCID were identified by chart review. On the basis of the number of deaths attributed to SCID on the Navajo Reservation, the authors estimate that the incidence of SCID in this population was 52 per 100,000 live births. Segregation analysis of 24 families was done to obtain a disease-gene frequency of $2.1 \%$. The authors considered this percentage to be a conservative estimate..$^{20}$ Another study examined SCIDA alleles in unrelated Navajo adults who were not related to SCIDA-affected families. Three of the 30 individuals tested were carriers for the SCIDA mutation. This finding suggests that the gene frequency may be higher than $2.1 \%{ }^{21}$ 
ADA

The ADA gene comprises 10 exons spanning 33,003 base pairs. ${ }^{1}$ Sixty $A D A$ mutations in 59 unrelated families have been identified in SCID-affected individuals. Fifty-four of the mutations are unique. ${ }^{24}$ Of these 54 mutations, 37 are missense mutations, 9 are splice-site mutations, 4 are frameshift deletions, 3 are nonsense mutations, and 1 is an inframe and gross deletion. $^{22,24}$ There is evidence of a genotype-phenotype correlation for severe and mild forms of $A D A$ related SCID. Milder forms of SCID are thought to be caused by mutations that result in decreased, but not absent, ADA enzyme function..$^{22-25}$

Buckley $^{5}$ reported on the genetic distribution in 160 SCID infants treated consecutively over a period of three decades at Duke University Medical Center in Durham, NC, a major referral center in the southeastern United States. In this population, $44 \%$ of the cases were attributed to mutations in IL2RG, $10 \%$ to mutations in $I L 7 R, 16 \%$ to mutations in $A D A, 6 \%$ to mutations in JAK3, and 3\% to mutations in RAG. The remainder of the cases were attributed to unknown genes. ${ }^{5} \mathrm{~A}$ retrospective single-center study of 117 SCID patients in Europe reported that patients with X-linked SCID (presumably IL2RG mutations) represented $28.2 \%$ of the cases, and ADA deficiency represented $13.7 \%$. Autosomal-recessive non-ADA SCID, in which the patients lacked both $\mathrm{T}$ cells and $\mathrm{B}$ cells $\left(\mathrm{T}^{-} \mathrm{B}^{-}\right)$accounted for at least $30.8 \%$ of the cases, and Omenn syndrome (specific RAG1 or 2 defects) represented $11.1 \% .^{26}$
Although comparison of these two series is difficult, it appears that autosomal recessive, non- $A D A, \mathrm{~T}^{-} \mathrm{B}^{-}$forms of SCID (RAG1/2, ARTEMIS) have a different genetic distribution in Europe than in the United States.

\section{Prevalence of SCID}

Although no population-based prevalence data exist on gene variants or on clinical SCID, several countries have developed registries to collect information about cases of primary immunodeficiency diseases, including SCID. The minimum prevalence of SCID (clinical cases) was estimated using data collected from these immunodeficiency registries. We reviewed data from registries (the only available epidemiologic data existing for SCID) that met certain criteria. These registries included a description of methods describing an attempt to collect facility-based data on clinically recognized SCID cases in a defined geographic area to estimate the minimum prevalence of SCID. The authors stated that they used a standard case definition, such as the one specified by the World Health Organization (WHO) ${ }^{27}$ for the case definition of SCID. These studies are identified in Table 2. Generally, data for these registries were collected by surveying hospital personnel and immunologists based in these countries. The cases in each registry were categorized by disorder, as defined by WHO. Minimum prevalence estimates were based on the frequency of reported cases of SCID per estimated population at risk. The

Table 2

Registries

\begin{tabular}{|c|c|c|c|c|c|c|}
\hline Study site (Ref) & Population sampled & Years included & Response & $\begin{array}{l}\text { SCID estimated incidence } \\
\text { and/or prevalence }\end{array}$ & $\begin{array}{l}\text { No. of cases } \\
\text { SCID/PID }\end{array}$ & Limitations \\
\hline Australia (28) & $\begin{array}{l}\text { Longitudinal cross-sectional } \\
\text { survey of immunologists } \\
\text { (ASCIA members) and } \\
\text { tertiary referral from all } \\
\text { clinical immunology } \\
\text { departments in pediatrics } \\
\text { and general hospitals. } \\
\text { Patients currently } \\
\text { receiving care or recently } \\
\text { deceased. }\end{array}$ & $\begin{array}{l}\text { Jan 1990-March } \\
1994\end{array}$ & $\begin{array}{l}\text { First } 500 \text { cases registered } \\
23 / 27 \text { hospitals and } 6 \\
\text { clinicians }\end{array}$ & $\begin{array}{l}\text { Prevalence of PID }= \\
2.82 / 100,000 \\
\text { Prevalence of SCID }= \\
0.15 / 100,000^{a}\end{array}$ & $\begin{array}{l}26 / 500 \\
5.2 \%\end{array}$ & $\begin{array}{l}\text { Ascertainment bias } \\
\text { Under-reporting } \\
\text { Facility-based, not } \\
\text { population-based }\end{array}$ \\
\hline Norway (30) & $\begin{array}{l}\text { Solicited PID cases from } \\
\text { survey of } 60 \text { hospitals (all } \\
\text { nonpsychiatric hospitals } \\
\text { in Norway). }\end{array}$ & $1961-1998$ & $\begin{array}{l}\text { 35/60 responded. Most } \\
\text { of the other } 25 \text { were } \\
\text { contacted; none had } \\
\text { any cases. }\end{array}$ & $\begin{array}{l}\text { Birth prevalence SCID = } \\
8.9(1.5-9.3) \text { per } \\
1,000,000 \text { live births } \\
\text { Prevalence SCID }= \\
0.045 / 100,000^{b}\end{array}$ & $\begin{array}{l}7 / 372 \\
1.9 \%\end{array}$ & $\begin{array}{l}\text { Ascertainment bias } \\
\text { Under-reporting } \\
\text { ICD9 code limitations } \\
\text { Poor response rate }\end{array}$ \\
\hline Sweden (31) & $\begin{array}{l}\text { Survey of all } 41 \text { children's } \\
\text { hospitals in Sweden }\end{array}$ & $\begin{array}{l}1974-1979 \\
\quad \text { (children } \leq \\
16 \text { yrs) }\end{array}$ & All responded & $\begin{array}{l}\text { Birth prevalence SCID = } \\
1.4 / 100,000 \text { live births }\end{array}$ & $\begin{array}{l}8 / 174 \\
4.6 \%\end{array}$ & $\begin{array}{l}\text { Ascertainment bias } \\
\text { Under-reporting }\end{array}$ \\
\hline $\begin{array}{l}\text { Switzerland } \\
\text { (29) }\end{array}$ & $\begin{array}{l}\text { Survey of } 12 \text { medical centers } \\
\text { or departments }\end{array}$ & $\begin{array}{l}\text { January 1975- } \\
\text { Jan } 1985\end{array}$ & Unknown & $\begin{array}{l}\text { Birth prevalence SCID = } \\
2.43 / 100,000 \text { live births } \\
\text { Prevalence SCID }=0.47 / \\
100,000^{c}\end{array}$ & $\begin{array}{l}28 / 313 \\
8.9 \%\end{array}$ & $\begin{array}{l}\text { Ascertainment bias } \\
\text { Under-reporting }\end{array}$ \\
\hline
\end{tabular}

\footnotetext{
${ }^{a}$ Australia: Primary immunodeficiency (PID) prevalence $=2.82 / 100,000$. SCID represented $5.2 \%$ of PID; calculated prevalence of SCID $=(0.052)(2.82 / 100,000)=$ $0.15 / 100,000$.

${ }^{b}$ Norway: Prevalence of combined immunodeficiency disorders $(C I D)=0.45 / 100,000$, SCID represented $10 \%$ of CID; calculated prevalence of SCID $=(0.1)(0.45 /$ $100,000)=0.045 / 100,000$.

'Switzerland: Three living SCID patients/6,423,100 population $=0.47 / 100,000$.
} 
prevalence of SCID was estimated to be $0.11 / 100,000,0.47 /$ 100,000 , or 0.045/100,000 in Australia, Switzerland, and Norway, respectively. ${ }^{28-30}$ Switzerland, Norway, and Sweden estimated the birth prevalence of SCID to be $2.43 / 100,000,0.89$ / 100,000 , or 1.4/100,000 live births, respectively ${ }^{29-31}$ (Table 2).

Prevalence is a measure of the proportion of affected patients who are alive at a particular point in time compared with the overall population. The prevalence of a disorder is affected by how long an individual with the disease survives after birth. The survival of SCID patients after birth is dependent on such factors as timely diagnosis and the availability of appropriate medical care and treatment. Therefore, population-based data on birth prevalence are needed. These data could be obtained through population-based surveillance or through assessment of population-based blood specimens to evaluate TCLP or clinical phenotype.

Unfortunately, these registry data underestimate the true prevalence of SCID. This underestimate can be attributed to lack of clinical recognition, lack of reporting to the registries, overrepresentation of certain referral centers, lack of a standardized case definition, and death of the infants before diagnosis. In addition, none of these studies are truly population based. The effect of these factors may vary between studies and between different countries and is correlated with the accessibility to or availability of medical care to the population. Finally, these studies define SCID phenotypically and not genotypically and may therefore include or exclude different disorders in their SCID category, making comparisons difficult.

\section{Clinical features of SCID}

SCID is a primary immunodeficiency disease caused by mutations in a number of genes involved in various aspects of B-cell and T-cell development. SCID is fatal without treatment and is characterized by the lack of a functional cellular and humoral immune system. Almost all patients have absent or very low T-cell number and function (TCLP). Total lymphocyte counts in these patients are usually $<1,500$ to 2,000 cells/ $\mathrm{mm}^{3}$ (normal 4,000-13,500 cells $/ \mathrm{mm}^{3}$ ); CD3 + T-cell counts are usually $<500$ cells $/ \mathrm{mm}^{3}$ (normal range 3,000 $-6,500$ cells/ $\mathrm{mm}^{3}$ ). ${ }^{32-34}$ The number of $\mathrm{B}$ and NK cells varies according to the underlying genetic defect. ${ }^{3-35}$ (Table 1). In a few rare cases, maternal engraftment of $\mathrm{T}$ cells may cause near-normal T-cell counts.

\section{Symptoms at presentation}

Patients with SCID usually present in the first few months after birth with a typical constellation of symptoms and signs, including failure to thrive as well as severe and persistent or recurrent infections. Other suggestive symptoms are persistent diarrhea, rashes, recurrent sinopulmonary infections, recurrent skin infections, abscesses, and poor wound healing. ${ }^{36,37}$ Pathogens include microbial organisms, such as Pseudomonas and Salmonella species; protozoa; and fungi, such as Pneumocystis carinii and Candida albicans; as well as viruses, such as respiratory syncytial virus, parainfluenza, cytomegalovirus, and adenovirus. SCID patients may develop graft-versus-host disease caused by maternal T-cell engraftment or postnatal transfusions. ${ }^{38}$ Physical examination reveals that these children do not have lymph nodes or tonsils. ${ }^{39} \mathrm{X}$-ray imaging and autopsies have shown that these patients have a small thymus lacking thymocytes.

SCID caused by certain genotypes can also result in unique symptoms. For example, mutations in the IL2RG gene is Xlinked and occurs in males. Approximately $85 \%$ to $90 \%$ of patients with mutations in $A D A$ present as infants with severe immunodeficiency. The remaining cases are milder, with a progressive onset after 2 years of age and even as late as adulthood. ${ }^{23,40}$ About $50 \%$ of children with infantile-onset ADA deficiency have skeletal deformities. ${ }^{23,40-42}$ These children also may have neurological symptoms, behavior problems, and a decreased IQ.43,44 Children affected with SCIDA often have oral or genital ulcers not seen in other forms. ${ }^{45}$ Further population-based data are needed on genotype-phenotype relations.

The pattern of lymphopenia characteristic of SCID varies with the type of SCID (Table 1). Patients with SCID caused by ADA deficiency have very few $\mathrm{T}, \mathrm{B}$, and NK cells or none at all (T-B-NK-SCID). SCID caused by mutations in genes involved in DNA recombination (RAG1, RAG2, and ARTEMIS) is $\mathrm{T}^{-} \mathrm{B}^{-}$but $\mathrm{NK}^{+}$. Mutations in genes needed for multiple cytokine receptor signaling (IL2RG and JAK3) cause $\mathrm{T}^{-} \mathrm{B}^{+} \mathrm{NK}^{-}$ SCID, whereas mutations in IL7R and CD45 cause $\mathrm{T}-\mathrm{B}^{+} \mathrm{NK}^{+}$ SCID (Fig. 1). Lymphocyte profiles are determined by subset analysis using flow cytometry. ${ }^{46}$ Patients with $\mathrm{B}^{+}$forms of SCID often have normal or elevated levels of nonfunctional B cells. These lymphocyte profiles may be altered by the presence of maternal lymphocytes that cross the placenta during gestation. ${ }^{33}$

\section{Treatment}

Successful treatment of SCID involves transplantation of hematopoietic stem cells from HLA-identical or haploidentical T-cell-depleted bone marrow. Myers et al. ${ }^{47}$ and Buckley et al. ${ }^{48}$ analyzed the survival of infants who received transplants within the first 3 months of life. The survival rate for infants transplanted at this center, before about 3 months of age, was $95 \%$, compared with a survival rate of approximately $75 \%$ for infants receiving treatment at a later age. These children, who are more than 8 months to 19 years posttransplant, developed normal levels of T cells and low-to-normal levels of NK cells. Unlike T cells, B-cell function was not normal after transplantation in many cases; thus, posttransplant recipients may require ongoing immunoglobulin replacement (IVIG) and antibiotics. Treatment earlier in infancy may be more successful, because it is administered before the onset of opportunistic infections that may cause death or morbidity before immune reconstitution can be achieved.

A recent report analyzed long-term survival of 475 SCID patients from 37 centers in 18 European countries who were treated between 1968 and 1999.49 This group includes 51 
(11\%) with $A D A, 137$ (29\%) who were phenotypically $\mathrm{T}^{-} \mathrm{B}^{-}$, $217(46 \%)$ who were phenotypically $\mathrm{T}-\mathrm{B}^{+}, 58(12 \%)$ identified as "other," and $12(3 \%)$ with reticular dysgenesis. Threeyear survival and engraftment was $77 \%$ and $54 \%$ for HLAidentical or HLA-haploidentical transplantation, respectively. Variables that affected survival rate for HLA-identical transplants included age at transplantation and the use of chemoprophylaxis. The 3-year survival rate for HLA-identical transplant recipient was $85 \%$ for patients younger than 6 months of age at the time of the transplant, $73 \%$ for those who were 6 to 11 months, and $53 \%$ for those who were 12 months or older. For non-HLA-identical transplants, patients with a B- phenotype had lower survival rate than SCID patients with a $\mathrm{B}^{+}$ phenotype. Patients in this group also had a higher survival rate if they received care in a protected environment and did not have a pulmonary infection prior to transplant. Survival rates for all types of SCID patients have increased over time.

There are many differences in treatment protocols among different doctors, centers, and countries, making comparisons of outcomes challenging. These differences include the protocols for T-cell depletion of donor bone marrow as well as pretransplant and posttransplant chemotherapy. ${ }^{50,51}$ Currently, multicenter trials have started to evaluate different protocols for hematopoietic stem cell transplant for SCID (L. Kobrynski, Emory University, personal communication, 2003).

Gene therapy has been used in clinical trials to treat $11 \mathrm{pa}-$ tients with SCID who had mutations in IL2RG $(\gamma \mathrm{c}) .^{52,53}$ Autologous $\mathrm{CD} 34^{+}$bone marrow cells were transduced ex vivo with a replication incompetent retroviral vector containing a normal gene encoding the $\gamma c$-chain. Initial results (2.5 years after treatment) in four patients indicate that they had nearly normal T-cell numbers and phenotypes. These $\mathrm{T}$ cells also had nearly normal repertoires of T-cell receptors and in vitro proliferative responses to antigens. Although the frequency of transduced B cells was low, these children did not require immunoglobulin replacement. ${ }^{53}$ One patient underwent stemcell transplantation 8 months after gene therapy because T-cell reconstitution failed. ${ }^{53}$ Two of the patients developed a form of leukemia because the retroviral gene construct of the IL2RG gene was inserted near the LMO2 gene, ${ }^{54-56}$ which resulted in insertional mutagenesis.

Gene therapy is being developed for other forms of SCID, ${ }^{57}$ including SCID caused by mutations in the $A D A$ gene. ${ }^{58-61}$ In one study, two patients with ADA-SCID received gene therapy using a retroviral vector containing the normal ADA gene. After treatment, both children had increased lymphocyte counts, improved immune functions, and lower levels of ADA and purine metabolites. Both patients were clinically well and developing normally. Neither patient required PEG-ADA therapy. ${ }^{60}$

Enzyme replacement is an option for patients who have SCID that is caused by mutations in the $A D A$ gene and who are unable to receive hematopoietic stem cell transplants. Twiceweekly injections of PEG-ADA, although very costly, have been shown to improve cellular immune function and increase the number of T lymphocytes. ${ }^{62-64}$

\section{INTERACTIONS}

\section{Infectious disease}

Because of the lack of a functional immune system, SCID patients are unusually susceptible to bacterial sepsis and to viral and fungal infections. Patients present in the first few months of life with frequent, severe, and persistent infections that do not respond to usual therapy. Without hematopoietic stem cell transplants, enzyme replacement, or gene therapy to correct their T-cell defects, patients with SCID will most likely die from a severe infection within the first year of life.

\section{Immunizations}

Vaccination with live attenuated vaccines such as oral poliovirus vaccine, smallpox, tuberculosis, measles and mumps and rubella, varicella, typhoid, and yellow fever can cause severe or fatal infections in SCID patients and should be avoided. ${ }^{65-69}$ Killed or inactivated vaccines such as inactivated poliovirus vaccine, diphtheria and tetanus toxoids and pertussis, and $\mathrm{He}$ mophilus influenzae type b may be given to SCID patients, although these children are unlikely to produce specific antibodies because of their immune defect. Passive immunoprophylaxis can be achieved by administering specific immune globulins after exposure to diseases such as measles, chicken pox, hepatitis B, tetanus, smallpox, and rabies. ${ }^{66}$ Passive antibody protection can be provided through monthly infusions of IVIG.

\section{Age of diagnosis}

Most children are diagnosed after developing severe or persistent infection, usually before 6 months of age (symptomatic screening). Children with affected siblings or other family members may be tested prenatally or at birth (asymptomatic screening).

\section{Family history}

Family history is an important diagnostic tool for identifying of patients affected with rare disorders. A patient who has previously diagnosed siblings or siblings who died of infections in infancy is suggestive of either X-linked or autosomal recessive SCID. A family history of unexplained deaths of male infants along maternal bloodlines may suggest an $\mathrm{X}$-linked recessive disorder such as IL2RG SCID. Autosomal recessive forms of SCID may occur in children of either sex. Family history may be ambiguous, however, because of undiagnosed cases in the past or because of de novo mutations. ${ }^{13,37}$ A study by Puck et al. ${ }^{13}$ examined the frequency and variety of $I L 2 R G$ mutations in 103 unrelated SCID-affected males and their relatives. In $62 \%$ of the IL $2 R G$ cases, there was no family history of X-linked SCID. In $13 \%$ of all IL2RG cases studied (and 23\% of sporadic $I L 2 R G$ cases), the mother of the SCID patient did not show skewed $\mathrm{X}$ chromosome inactivation, which is indicative of an IL2RG carrier. These new IL2RG mutations occurred as a result of maternal mosaicism or within the oocyte. ${ }^{13}$ There are no population-based data for the allele frequencies of any of the mutations that cause SCID. 


\section{ASSOCIATIONS}

Associations between SCID and the genes in this review have been determined by molecular and DNA-based methods. Currently, no literature on epidemiologic-based associations exists. The relative, absolute, and attributable risks for these genes related to SCID are unknown. All mutations reported in the literature cause SCID. The penetrance of mutations in these genes is unknown. Current literature deals with case-only series.

Because of the lack of information on the distribution of genotypes in the population, data are scarce regarding genotype-phenotype relations. Different mutations in the same gene can cause a spectrum of disease phenotypes; therefore, we are probably only aware of the more severe cases. ${ }^{70}$ Mutations that cause a less severe phenotype have been identified in RAG1, RAG2, ADA, JAK3, and IL2RG. More severe mutations, such as deletions or frameshifts of the RAG1 or RAG2 genes, result in the SCID phenotype. ${ }^{71}$ Some mutations (mostly missense) in RAG 1 and RAG2 impair, but do not abolish, the function of these enzymes. These mutations cause Omenn syndrome, a primary immune deficiency affecting the maturation of $\mathrm{T}$ and $\mathrm{B}$ lymphocytes that is clinically distinct from SCID. ${ }^{40,71-73}$ Patients with Omenn syndrome have a variable number of nonfunctional $\mathrm{T}$ cells and undetectable levels of $\mathrm{B}$ cells. These patients also have a number of other clinical features, including erythroderma, lymphadenopathy, and hepatosplenomegaly. Corneo et al. ${ }^{74}$ have reported on several patients with the same RAG1 or RAG2 mutations. Some of these patients had SCID, and others had Omenn syndrome. Other factors, such as timing of treatment, stochastic events, environmental factors, or other genetic factors may also affect the phenotype of RAG1 and RAG2 mutations. ${ }^{71,74}$

Mutations in $A D A$ that decrease but do not abolish enzyme activity can cause immune deficiencies with later onset and more mild phenotypes. ${ }^{22,75-77}$ Siblings and unrelated individuals who carry the same $A D A$ mutations can have different phenotypes. These differences may be due to differences in environmental factors or to other genetic factors. ${ }^{78}$ Somatic mosaicism has also been observed in two cases of ADA SCID. These patients showed clinical improvement without therapy. In one case, not all of the cells carried the $A D A$ mutation; in the other case, the point mutation reverted in somatic cells. ${ }^{40,79}$ Other patients, who had no ADA enzyme activity in erythrocytes, were immunologically normal as a result of activity in other cell types. ${ }^{77,80,81}$

Frucht et al. ${ }^{82}$ have described two and possibly three siblings with identical mutations in JAK3 who had different clinical phenotypes. Each sibling had an A96G initiation start-site mutation that encoded a dysfunctional product and another allele with a splice donor-site mutation that is predicted to cause premature termination of JAK3. One sibling had extremely low JAK3 levels and the other had no detectable JAK3, consistent with his more severe phenotype. The authors speculate that other genetic factors may have affected the phenotypes in these siblings. ${ }^{82}$ Other groups have also reported milder forms of JAK3 SCID. ${ }^{14}$ Mutations in IL2RG that confer a mild SCID phenotype have also been identified. ${ }^{70}$ Standardized clinical case definitions for SCID are needed. A less severe form of SCID may also need to be defined to more broadly assess genotype-phenotype relations.

\section{Laboratory tests}

Most SCID patients have lymphopenia with total lymphocyte counts of $<2,000$ lymphocytes $/ \mathrm{mm}^{3}$ (normal newborn range is 2,000-5,500 lymphocytes $/ \mathrm{mm}^{3}$; normal range at 6 months is $4,000-13,500$ lymphocytes $/ \mathrm{mm}^{3}$ ). All patients have few $\mathrm{T}$ cells or none at all and, depending on the form of SCID, some may have few B and NK cells or none at all. Lymphopenia can be detected prenatally or after birth by obtaining a whiteblood-cell count and differential. Patients with some forms of SCID can have abnormally high levels of B cells, which can mask TCLP and may cause the total lymphocyte count to appear normal. Subset analysis by flow cytometry is therefore necessary to enumerate T, B, and NK cells. ${ }^{46}$ Diagnostic tests analyze $\mathrm{T}$-cell function by using in vitro responses of peripheral blood lymphocytes to phytomitogens and common antigens. B-cell function is measured by looking at serum immunoglobulins and specific antibodies. Both T-cell and B-cell function are abnormal in SCID; however, patients may appear to have some function as a result of transplacental passage of maternal cells and immunoglobulins. ADA enzyme activity in leukocytes can be measured to confirm diagnosis of SCID caused by defects in the $A D A$ gene. This test has a very high sensitivity and specificity for SCID caused by ADA mutations.

Diagnosis can be confirmed by DNA-sequence analysis of the gene(s) suggested by the lymphocyte profile. Mutations in unidentified gene(s) cause approximately $18 \%$ of SCID. ${ }^{5} \mathrm{Se}-$ quence analysis of the known genes will not confirm a diagnosis in these cases. Many mutations known to cause SCID are due to genetic alterations affecting the sequence of the protein, which results in the production of a full-length but nonfunctional protein. Thus, other potential tests, such as protein detection may not be diagnostic.

In families that have previously affected members, SCID can be diagnosed prenatally if the mutated gene is known. DNA sequence analysis can be performed on fetal cells collected by chorionic villus biopsy or amniocentesis. Umbilical-cord blood can be analyzed for ADA enzyme levels and TCLP. ${ }^{36,77,83}$ DNA-based tests have been developed to diagnose SCID caused by mutations in ADA, IL2RG, SCIDA, RAG, and JAK3 prenatally. ${ }^{21,77,84-86}$

Carriers in high-risk families can be identified by DNA-sequence analysis if the affected gene is known. Female carriers of IL2RG mutations can be identified by nonrandom X-chromosome inactivation in lymphoid cells ${ }^{87}$ and a variety of other molecular techniques. ${ }^{86}$

\section{Population testing}

Many characteristics of SCID make this disorder a good candidate for newborn screening, as defined by Wilson and Jungner88: (1) SCID is an important health problem, and it is fatal in 
infancy without immune reconstitution; (2) a short asymptomatic period exists after birth; (3) effective treatments are available; (4) early intervention improves outcome; and (5) profound deficiencies of cellular and humoral immunity may be detectable with screening tests. No population testing currently exists for SCID, although New York had a program to detect children with ADA deficiencies in the 1970s using a colorimetric test based on ADA enzyme activity. ${ }^{89,90}$ Of the 2.56 million newborns screened over a 12 -year period, no cases of ADA SCID were detected. Two cases that were not detected by screening were reported during this time period. Twelve cases of partial ADA deficiency were detected by the program. However, all of these patients who lacked ADA in erythrocytes, but who had substantial ADA activity in other cell types, had normal immune function. ${ }^{77,91}$ These results lead to the discontinuation of ADA screening in New York.

Nearly every newborn in the United States is screened for a minimum of four and a maximum of about 30 metabolic, hematologic, or endocrinological disorders depending on the state in which they are born. Several drops of blood collected from each baby are applied to filter paper and dried. This simple, easily transported, and inexpensive specimen-collection method allows for the assay of over 30 disorders from a single drop of blood. Detecting TCLP from dried blood spots (DBS) would be the most efficient way to integrate SCID screening into the existing newborn screening system. This practice is possible, in principle, because DBS contain mummified T cells (and other leukocytes); however, a high-throughput test based on direct visualization from the DBS is not feasible.

Work by Dr. R. Buckley at Duke University compared lymphocyte levels between normal and SCID babies at birth has shown that most SCID patients had low absolute lymphocyte counts at birth (range of absolute lymphocyte counts was 1142210 lymphocytes $/ \mathrm{mm}^{3}$ for 25 SCID newborns and 1670-8910 lymphocytes $/ \mathrm{mm}^{3}$ for 14 normal infants at birth) (Fig. 2). All of the patients had very low T-cell counts (range of T-cell counts for SCID infants was 0-84 lymphocytes $/ \mathrm{mm}^{3}$ and for normal infants was 903-7226 lymphocytes $/ \mathrm{mm}^{3}$ at

\section{Absolute Lymphocyte Count}

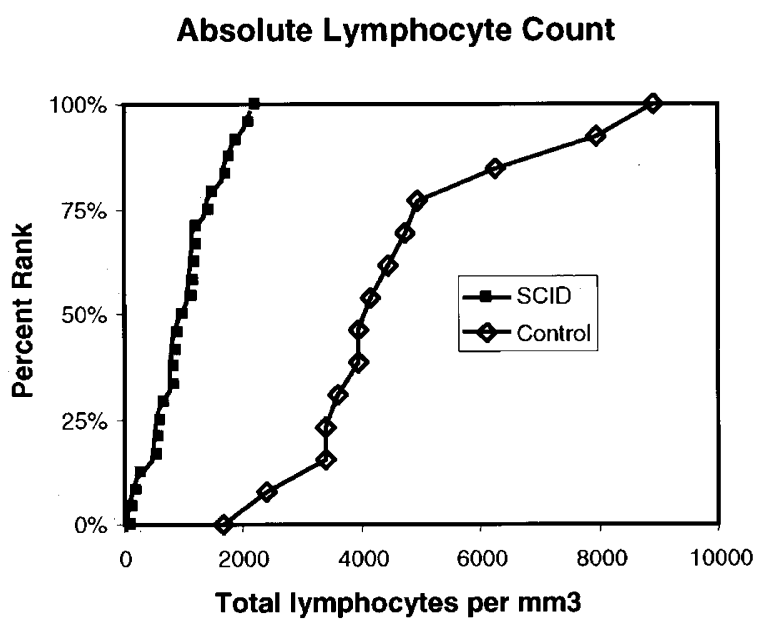

birth). These data suggest that T-cell counts could be a sensitive indicator of SCID and that total lymphocyte counts may not identify the $10 \%$ to $20 \%$ of SCID patients whose high B-cell counts gave them a misleadingly normal lymphocyte count.

Several types of soluble T-cell-specific biomarkers, which can theoretically be recovered from DBS, may serve as potential surrogates for a T-cell count. The first type of biomarker is the family of cell membrane proteins unique to $\mathrm{T}$ cells, most notably CD3. Measurements of CD3 eluted from cultured T cells have shown strong correlation with T-cell count, ${ }^{92}$ but this method has not yet been tested in whole blood or blood spots. Measurements of eluted CD4 also correlate strongly with T-cell counts, and this method has been applied successfully to whole blood and to DBS. ${ }^{93}$ Because the CD4 protein is also expressed (at lower levels) on monocytes, this marker is not as T-cell specific as CD3, but it offers another viable option.

The second type of T-cell biomarker is the circular DNA that is removed when T-cell receptor variable genes rearrange, often called T-cell antigen receptor excision circles (TRECs). ${ }^{47,94}$ DNA is well preserved on DBS, and detection of TRECs should be possible, ${ }^{95}$ but accurate quantification may be difficult after polymerase chain reaction amplification, especially for high throughput applications, such as newborn screening.

Although DNA is well preserved on DBS, the wide variety of genetic mutations that can cause SCID and the lack of knowledge about the effects and severity of particular mutations rule out screening tests based on genomic DNA analysis. Total lymphocyte counts, when obtained in a complete blood count, would probably not be an adequate screen for SCID, because affected newborns can have increased B-cell counts, producing a $10 \%$ to $20 \%$ overlap with the normal lymphocyte distributions. ${ }^{47}$ Subset analysis by flow cytometry would be necessary to enumerate T, B, and NK cells. ${ }^{46}$ This test could not be done on DBS.

To be clinically useful, each of these tests must be developed and must undergo population-based evaluation to determine its specificity and validity. Potential confounding variables include the possible detection of lymphopenia due to genetic

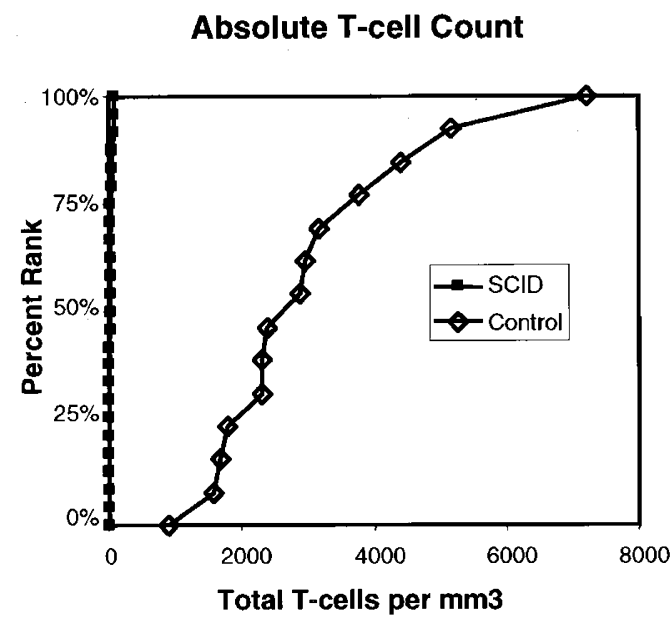

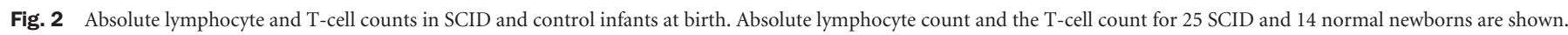


causes, such as DiGeorge syndrome or cartilage hair hypoplasia, or by HIV infection. However, although these children do not have SCID, they nevertheless are affected by a serious immunologic deficiency that requires evaluation. Screening tests not only would identify children with a fatal but treatable disease, but also could provide valuable information regarding the incidence of these disorders in the population, information about their penetrance, and the frequency of mutations among affected individuals. Population-based data on the frequency of mutations in each of the genes that cause SCID could also be obtained.

\section{CONCLUSIONS AND RECOMMENDATIONS FOR RESEARCH}

Without prompt diagnosis and treatment, children with SCID die in their first year of life. Data suggest that children born with this condition would benefit from presymptomatic detection and treatment. Much work needs to be done to assess the epidemiology of the genetic conditions that underlie SCID. An active case ascertainment that uses a standardized case definition, which includes genetic tests in a defined geographical area over a defined time period, would provide a more complete accounting of cases and an accurate estimate of the incidence and prevalence of SCID. An ascertainment of the prevalence of SCID-associated mutations and disease in different populations is also needed. Tests need to be developed that use DBS to detect TCLP. Pilot studies regarding newborn screening could provide data on the incidence of SCID in the population as well as information on the phenotype of various mutations.

\section{References}

1. National Center for Biotechnology Information, 2003. Available at: http://www.ncbi.nlm.nih.gov.

2. Puel A, Ziegler S, Buckley R, Leonard W. Defective IL7R expression in T-B+NK+ severe combined immunodeficiency. Nat Genet 1998;20:394-397.

3. Online Mendelian Inheritance in Man, OMIM. McKusick-Nathans Institute for Genetic Medicine, Johns Hopkins University (Baltimore, MD), and National Center for Biotechnology Information, National Library of Medicine (Bethesda, MD), 2002. Available at: http://www.ncbi.nlm.nih.gov/htbin-post/ Omim/dispmim?146661\&field=title.

4. The Human Gene Mutation Database. Interleukin 7 Receptor. Institute of Medical Genetics, University of Wales College of Medicine (Cardiff, Wales), 2003. Available at: http://archive.uwcm.ac.uk/uwcm/mg/hgmd0.html.

5. Buckley RH. Primary cellular immunodeficiencies. Current reviews of allergy and clinical immunology. J Allergy Clin Immunol 2002;109:747-757.

6. Kung C, Pingel JT, Heikinheimo M, Klemola T, Varkila K, Yoo LI et al. Mutations in tyrosine phosphatase CD45 gene in a child with severe combined immunodeficiency disease. Nat Med 2000;6:343-345.

7. Tchilian EZ, Wallace DL, Wells RS, Flower DR, Morgan G, Beverly PCL. A deletion in the gene encoding the CD45 antigen in a patient with SCID. J Immunol 2001; 166:1308-1313.

8. Cale CM, Klein NJ, Novelli V, Veys P, Jones AM, Morgan G. Severe combined immunodeficiency with abnormalities in expression of the common leukocyte antigen, CD45. Arch Dis Child 1997;76:163-164.

9. National Human Genome Research Institute, 2003. Available at: http://www.nhgri.nih.gov/DIR/GMBB/SCID/IL2RGbase.html.

10. Pepper A, Buckley R, Small T, Puck J. Two mutational hotspots in the interleukin-2 receptor gamma chain gene causing $\mathrm{X}$-linked severe combined immunodeficiency. Am J Hum Genet 1995;57:564-571.
11. Russell S, Johnston J, Noguchi M, Kawamura M, Bacon CM, Friedmann M et al. Interaction of IL-2R beta and gamma c chains with Jak1 and Jak3: implications for XSCID and XCID. Science 1994;266:1042-1045.

12. DiSanto J, Rieux-Laucat F, Dautry-Varsat A, Fischer A, de Saint Basile G. Defective human interleukin 2 receptor gamma chain in an atypical $\mathrm{X}$ chromosome-linked severe combined immunodeficiency with peripheral T cells. Proc Natl Acad Sci U S A 1994;91:9466.

13. Puck J, Pepper A, Henthorn P, Candotti F, Isakov J, Whitwam T et al. Mutation analysis of IL2RG in human X-linked severe combined immunodeficiency. Blood 1997;89:1968-1977.

14. Notarangelo LD, Mella P, Jones A, de Saint Basile G, Savoldi G, Cranston T et al. Mutations in severe combined immune deficiency (SCID) due to JAK3 deficiency. Hum Mutat 2001;18:255-263.

15. JAK3base. Mutation Registry for Autosomal Recessive Severe Combined JAK3 Deficiency. Institute of Medical Technology, IMT Bioinformatics, University of Tampere, (Tampere, Finalnd); European Society for Immunodeficiencies (ESID), 2003 Available at: http://www.uta.fi/imt/bioinfo/JAK3base/.

16. RAGlbase. Mutation Registry for Autosomal Recessive RAG1 Deficiency. Institute of Medical Technology, IMT Bioinformatics, University of Tampere, (Tampere, Finalnd); European Society for Immunodeficiencies (ESID), 2001. Available at: http://www.uta.fi/imt/bioinfo/RAGlbase/.

17. RAG2base. Mutation Registry for Autosomal Recessive RAG2 Deficiency. Institute of Medical Technology, IMT Bioinformatics, University of Tampere, (Tampere, Finalnd); European Society for Immunodeficiencies (ESID), 2001. Available at: http://www.uta.fi/imt/bioinfo/RAG2base/.

18. Li L, Moshous D, Zhou Y, Wang J, Xie G, Salido E et al. A founder mutation in Artemis, an SNM1-like protein causes SCID in Athabascan-speaking Native Americans. J Immun 2002;168:6323-6329.

19. Moshous D, Callebaut I, de Chasseval R, Corneo B, Cavazzana-Calvo M, Le Deist $\mathrm{F}$ et al. Artemis, a novel DNA double-strand break repair/V(D)J recombination protein, is mutated in human severe combined immune deficiency. Cell 2001;105: $177-186$.

20. Jones JF, Ritenbaugh CK, Spence MA, Hayward A. Severe combined immunodeficiency among the Navajo. I. Characterization of phenotypes, epidemiology, and population genetics. Hum Biol 1991;63:669-682.

21. Li L, Zhou Y, Wang J, Hu D, Cowan MJ. Prenatal diagnosis and carrier detection for Athabascan severe combined immunodeficiency disease. Prenat Diagn 2002;22: 763-768.

22. Arrendondo-Vega FX, Santisteban I, Daniels S, Toutain S, Hershfield MS. Adenosine deaminase deficiency: genotype-phenotype correlations based on expressed activity of 29 mutant alleles. Am J Hum Genet 1998;63:1049-1059.

23. Online Mendelian Inheritance in Man, OMIM. McKusick-Nathans Institute for Genetic Medicine, Johns Hopkins University (Baltimore, MD), and National Center for Biotechnology Information, National Library of Medicine (Bethesda, MD), 2002. Available at: http://www3.ncbi.nlm.nih.gov/htbin-post/Omim/disp$\operatorname{mim} ? 102700$.

24. ADAbase. Mutation Registry for Adenosine Deaminase Deficiency. Institute of Medical Technology, IMT Bioinformatics, University of Tampere, (Tampere, Finalnd); European Society for Immunodeficiencies (ESID), 2001. Available at: http://www.uta.fi/imt/bioinfo/ADAbase/.

25. Arrendondo-Vega F, Santisteban I, Notarangelo L, El Dahr J, Buckley R, Roifman $\mathrm{C}$ et al. Seven novel mutations in the adenosine deaminase (ADA) gene in patients with severe and delayed onset combined immunodeficiency: G74C, V129M, G140E, R149W, Q199P, 462delG, and E337del. Hum Mutat 1998;11:482.

26. Stephan JL, Vlekova V, Le Deist F, Blanche S, Donadieu J, De Saint-Basile G et al. Severe combined immunodeficiency: a retrospective single-center study of clinical presentation and outcome in 117 patients. J Pediatr 1993;123:564-572.

27. Primary immunodeficiency diseases: report of a WHO sponsored meeting. Immunodeficiency Rev 1989;1:173-205.

28. Baumgart K, Britton WJ, Kemp A, French M, Roberton D. The spectrum of primary immunodeficiency disorders in Australia. J Allergy Clin Immunol 1997;100: 415-423.

29. Ryser O, Morell A, Hitzig WH. Primary immunodeficiencies in Switzerland: first report of the national registry in adults and children. J Clin Immunol 1988;8:479485.

30. Stray-Pedersen A, Abrahamsen TG, Froland SS. Primary immunodeficiency diseases in Norway. J Clin Immunol 2000;20:477-485.

31. Fasth A. Primary immunodeficiency disorders in Sweden: cases among children. 1974-1979. J Clin Immunol 1982;2:86-92.

32. Shearer WT, Rosenblatt HM, Gelman RS, Oyomopito R, Plaeger S, Stiehm E et al. Lymphocyte subsets in healthy children from birth through 18 years of age: the Pediatric AIDS clinical trials group Study. J Allergy Clin Immunol. 2003;112:973980. 
33. Buckley RH, Schiff RI, Shiff SE, Markert ML, Williams LW, Harville TO et al. Human severe combined immunodeficiency: genetic, phenotypic, and functional diversity in one hundred eight infants. J Pediatr 1997;130:378-387.

34. Elder ME. T-cell Immunodeficiencies. Pediatr Clin North Am 2000;47:1253-1274.

35. Conley ME, Notarangelo LD, Etzioni A. Diagnostic criteria for primary immunodeficiencies. J Clin Immunol 1999;93:190-197.

36. IUIS Scientific Group. Primary immunodeficiency diseases: Report of an IUIS scientific committee. Clin Exp Immunol 1999;118:1-28.

37. Puck JM. Primary immunodeficiency diseases. JAMA 1997;278:1835-1841.

38. Belmont JW, Puck JM. T cell and combined immunodeficiency disorders. In: Schriver CR, Beaudet AL, Sly WS, Valle D, editors. The metabolic and molecular bases of inherited disease. New York: McGraw-Hill, 2003:4751-4783.

39. Buckley R. Primary immunodeficiency diseases due to defects in lymphocytes. $A d v$ Immunol 2000;343:1313-1324.

40. Ochs HD, Smith E, Puck J, editors. Primary immunodeficiency diseases: a molecular and genetic approach. New York: Oxford Press, 1999.

41. Cederbaum SD, Kaitila I, Rimoin DL, Stiehm ER. The chondrosseous dysplasia of adenosine daminase deficiency with severe combined immunodeficiency. J Pediatr 1976;89:737-742.

42. Hirschhorn R. Adenosine deaminase deficiency: molecular basis and recent developments. Clin Immunol 1995;76:S219-S227.

43. Hirschhorn R, Papageorgiou PS, Kesarwala HH, Taft LT. Amelioration of neurologic abnormalities after "enzyme replacement" in adenosine deaminase deficiency. N Engl J Med 1980;303:377-380.

44. Rogers MH, Lwin R, Fairbanks L, Gerritsen B, Gaspar HB. Cognitive and behavioral abnormalities in adenosine deaminase deficient severe combined immunodeficiency. J Pediatr 2001;139:44-50.

45. Kwong PC, O’Macaigh AS, Howard R, Cowan MJ, Frieden IJ. Oral and genital ulceration: a unique presentation of immunodeficiency in Athabascan-speaking American Indian children with severe combined immunodeficiency. Arch Dermatol 1999;135:927-931.

46. De Vries E, Noordzij JG, Kuijpers TW, van Dongen JJM. Flow cytometric immunophenotyping in the diagnosis and follow-up of immunodeficient children. Eur J Pediatr 2001;160:583-591.

47. Myers LA, Patel DD, Puck JM, Buckley RH. Hematopoietic stem cell transplantation for severe combined immunodeficiency in the neonatal period leads to superior thymic output and improved survival. Blood 2002;99:872-878.

48. Buckley RH, Schiff SE, Schiff RI, Markert ML, Williams LW, Roberts JL et al. Hematopoietic stem-cell transplantation for the treatment of severe combined immunodeficiency. N Engl J Med 1999;340:508-516.

49. Antoine C, Muller S, Cant A, Cavazzana-Calvo M, Veys P, Vossen J, Fasth A et al. Long-term survival and transplantation of haemopoietic stem cells for immunodeficiencies: Report of the European experience 1968-99. Lancet 2003;361:553560 .

50. Fischer A. Thirty years of bone marrow transplantation for severe combined immunodeficiency. N Engl J Med 1999;340:559-561.

51. Fischer A, Landais P, Friedrich W, Morgan G, Gerritsen B, Fasth A et al. European experience of bone-marrow transplantation for severe combined immunodeficiency. Lancet 1990;336:850-854.

52. Cavazzana-Calvo M, Hacein-Bey S, de Saint Basile G, Gross F, Yvon E, Nusbaum P et al. Gene therapy of human severe combined immunodeficiency (SCID)-X1 disease. Science 2000;288:669-672.

53. Hacein-Bey-Abina S, Le Deist F, Carlier F, Bouneaud C, Hue C, De Villartay JP et al. Sustained correction of X-linked severe combined immunodeficiency by ex vivo gene therapy. N Engl J Med 2002;346:1185-1193.

54. Kaiser J. Seeking the cause of induced leukemias in X-SCID trial. Science 2003;299: 495.

55. Marshall E. Second child in French trial is found to have leukemia. Science 2003; 299:320.

56. Hacein-Bey-Albina S, von Kalle C, Schmidt M, Le Deist F. A serious adverse event after successful gene therapy for X-linked severe combined immunodeficiency. N Engl J Med 2003;348:255-256.

57. Cavazzana-Calvo M, Hacein-Bey S, Yates F, De Villartay JP, Le Deist F, Fischer A. Gene therapy of severe combined immunodeficiencies. J Gene Med 2001;3:201206.

58. Blaese RM, Culver KW, Miller AD, Carter CS, Fleisher T, Clerici M et al. T lymphocyte-directed gene therapy for ADA-SCID: initial trial results after 4 years. Science 1995;270:475-480.

59. Bordignon C, Notarangelo LD, Nobili N, Ferrari G, Casorati G, Panina P et al. Gene therapy in peripheral blood lymphocytes and bone marrow for ADA-immunodeficient patients. Science 1995;270:470-475.

60. Aiuti A, Slavin S, Aker M, Ficara F, Deola S, Mortellaro A et al. Correction of ADA-SCID by stem cell gene therapy combined with nonmyeloablative conditioning. Science 2002;296:2410-2413.
61. Onodera M, Ariga T, Kawamura N, Kobayashi I, Ohtsu M, Yamada M et al. Successful peripheral T-lymphocyte-directed gene transfer for a patient with severe combined immune deficiency caused by adenosine deaminase deficiency. Blood 1998;91:30-36.

62. Hershfield MS, Buckley RH, Greenberg ML, Melton AL, Schiff R, Hatem C et al. Treatment of adenosine deaminase deficiency with polyethylene glycol-modified adenosine deaminase. N Engl J Med 1987;316:589-596.

63. Hershfield MS, Chaffee S, Sorensen RU. Enzyme replacement therapy with PEGADA in adenosine deaminase deficiency: Overview and case reports of three patients, including two now receiving gene therapy. Pediatr Res 1993;33(suppl):S42S48.

64. Hershfield MS. PEG-ADA: an alternative to haploidentical bone marrow transplantation and an adjunct to gene therapy for adenosine deaminase deficiency. Hum Mutat 1995;5:107-112.

65. Bellini WJ, Rota JS, Greer PW, Zaki SR. Measles vaccination death in a child with severe combined immunodeficiency: Report of a case. Lab Invest 1992;66:91A.

66. Centers for Disease Control, and Prevention. Recommendations of the Advisory Committee on Immunization Practices (ACIP): Use of vaccines and immunoglobulins in persons with altered immuno-competence. Mor Mortal Wkly Rep 1993;42:(RR-4).

67. Antaya RJ, Gardner ES, Bettencourt MS, Daines M, Denise Y, Uthaisangsook S et al. Cutaneous complications of BCG vaccination in infants with immune disorders: Two cases and a review of the literature. Pediatr Derm 2001;18:205-209.

68. Davis LE, Bodian D, Price D, Butler IJ, Vickers JH. Chronic progressive poliomyelitis secondary to vaccination of an immunodeficient child. N Engl J Med 1977; 297:241-245.

69. Han TI, Kim IO, Kim WS, Yeon KM. Disseminated BCG infection in a patient with severe combined immunodeficiency. Korean J Radiol 2000;1:114-117.

70. Notarangelo LD, Giliani S, Mazza C, Mella P, Savoldi G, Rodriguez-Perez C et al Of genes and phenotypes: the immunological and molecular spectrum of combined immune deficiency: Defects of the gc-JAK3 signaling pathway as a model. Immunol Rev 2000;178:39-48.

71. Villa A, Sobacchi C, Notarangelo LD, Bozzi F, Abinun M, Abrahamsen TG et al $\mathrm{V}(\mathrm{D}) \mathrm{J}$ recombination defects in lymphocytes due to RAG mutations: severe immunodeficiency with a spectrum of clinical presentations. Blood 2001;97:81-88.

72. Villa A, Santagata S, Bozzi F, Imberti L, Notarangelo LD. Omenn syndrome: A disorder of Rag1 and Rag2 genes. J Clin Immunol 1999;19:87-97.

73. Santagata S, Villa A, Sobacchi C, Cortes P, Vezzoni P. The genetic and biochemical basis of Omenn syndrome. Immunol Rev 2000;178:64-74.

74. Corneo B, Moshous D, Gungor T, Wulffratt N, Philippet P, Le Deist F et al. Identical mutations in RAG1 or RAG2 genes leading to defective $\mathrm{V}(\mathrm{D}) \mathrm{J}$ recombinase activity can cause either T-B-severe combined immune deficiency or Omenn syndrome. Blood 2001;97:2772-2776.

75. Santisteban I, Arrendondo-Vega FX, Kelly S, Mary A, Fischer A, Hummell DS et al. Novel splicing, missense, and deletion mutations in seven adenosine deaminasedeficient patients with late/delayed onset of combined immunodeficiency disease: Contribution of genotype to phenotype. J Clin Invest 1993;92:2291-2302.

76. Ozsahin H, Arredondo-Vega FX, Santisteban I, Fuhrer H, Tuchschmid P, Jochum W et al. Adenosine deaminase deficiency in adults. Blood 1997;89:2849-2855.

77. Hirschhorn R. Adenosine deaminase deficiency. Immunodeficiency Rev 1990;2:175-198.

78. Umetsu DT, Schlossman CM, Ochs HD, Hershfield MS. Heterogeneity of phenotype in two siblings with adenosine deaminase deficiency. J Allergy Clin Immunol 1994;93:543-550.

79. Hirschhorn R, Yang DR, Israni A, Huie ML, Ownby DR. Somatic mosaicism for a newly identified splice-site mutation in a patient with adenosine deaminase-deficient immunodeficiency and spontaneous clinical recovery. Am J Hum Genet 1994; 55:59-68.

80. Jenkins T, Lane AB, Nurse GT. Red cell adenosine deaminase (ADA) polymorphism in Southern Africa with special reference to ADA deficiency among the Kung. Ann Hum Genet 1979;24:425-433.

81. Ariga T, Oda N, Sanstisteban I, Arrendondo-Vega FX, Shioda M, Ueno H et al Molecular basis for paradoxical carriers of adenosine deaminase (ADA) deficiency that show extremely low levels of ADA activity in peripheral blood cells without immunodeficiency. J Immunol 2001;166:1698-1702.

82. Frucht DM, Gadina M, Jagadeesh GJ, Aksentijevich I, Takada K, Bleesing JJH et al Unexpected and variable phenotypes in a family with JAK3 deficiency. Genes Immun 2001;2:422-432.

83. Hirschhorn R. Prenatal diagnosis of adenosine deaminase deficiency and selected other immunodeficiencies. In: Milunsky A, editor. Genetic disorders and the fetus: diagnosis, prevention, and treatment. New York: Plenum Press, 1992:453-464.

84. Villa A, Bozzi F, Sobacchi C, Strina D, Fasth A, Pasic S et al. Prenatal diagnosis of RAG-deficient Omenn syndrome. Prenat Diagn 2000;20:56-59. 


\section{Kalman et al.}

85. Schumacher RF, Mella P, Lalatta F, Fiorini M, Giliani S, Villa A et al. Prenatal diagnosis of JAK3 deficient SCID. Prenat Diagn 1999;19:653-656.

86. Puck JM, Middelton L, Pepper AE. Carrier and prenatal diagnosis of X-linked severe combined immunodeficiency: Mutation detection methods and utilization. Hum Genet 1997;99:628-633.

87. Puck JM, Stewart CC, Nussbaum RL. Maximum-likelihood analysis of human T-cell X chromosome inactivation patterns: Normal women versus carriers of X-linked severe combined immunodeficiency. Am J Hum Genet 1992;50:742-748.

88. Wilson JMG, Jungner F. Principles and practice of screening for disease. World Health Organization (Geneva, Switzerland); 1968 Public Health Papers No. 34.

89. Amador PS, Carter TP. Historical review of newborn screening in New York state: Twenty years experience. In: Genetic disease: screening and management. Alan R. Liss, Inc., 1986:343-357.

90. Moore EC, Meuwissen HJ. Screening for ADA deficiency. J Pediatr 1974;85:802-804.

91. Hirschhorn R, Ellenbogen A. Genetic heterogeneity in adenosine deaminase (ADA) deficiency: five different mutations in five new patients with partial ADA deficiency. Am J Hum Genet 1986;38:13-25.

92. Lund-Johansen F, Davis K, Bishop J, de Waal Malefyt R. Flow cytometric analysis of immunoprecipitates: high-throughput analysis of protein phosphorylation and protein-protein interactions. Cytometry 2000;39:250-259.

93. Parsons G, Johns M, Rugg A. Dried blood spot samples for CD4 cell count determinations. Paper presented at the VII International Conference on AIDS. Florence, Italy June 16-21, 1991.

94. Hazenberg MD, Hamann D, Miedema F, van Dongen JJM. T cell receptor excision circles as markers for recent thymic emigrants: Basic aspects, technical approach, and guidelines for interpretation. J Mol Med 2001;79:631-640.

95. Chan K, Chinen J, Puck JM. Development of population based newborn screening for severe combined immunodeficiency. Clin Immunol 2003;suppl:S104.
96. Online Mendelian Inheritance in Man, OMIM. McKusick-Nathans Institute for Genetic Medicine, Johns Hopkins University (Baltimore, MD), and National Center for Biotechnology Information, National Library of Medicine (Bethesda, MD), 2002. Available at: http://www.ncbi.nlm.nih.gov/htbin-post/Omim/disp$\operatorname{mim} ? 308380$.

97. Online Mendelian Inheritance in Man, OMIM. McKusick-Nathans Institute for Genetic Medicine, Johns Hopkins University (Baltimore, MD), and National Center for Biotechnology Information, National Library of Medicine (Bethesda, MD), 2002. Available at: http://www.ncbi.nlm.nih.gov/htbin-post/Omim/ dispmim?600173\&field $=$ title.

98. Online Mendelian Inheritance in Man, OMIM. McKusick-Nathans Institute for Genetic Medicine, Johns Hopkins University (Baltimore, MD), and National Center for Biotechnology Information, National Library of Medicine (Bethesda, MD), 2002. Available at: http://www3.ncbi.nlm.nih.gov/htbin-post/Omim/disp$\operatorname{mim}$ ?179615.

99. Online Mendelian Inheritance in Man, OMIM. McKusick-Nathans Institute for Genetic Medicine, Johns Hopkins University (Baltimore, MD), and National Center for Biotechnology Information, National Library of Medicine (Bethesda, MD), 2002. Available at: http://www.ncbi.nlm.nih.gov/htbin-post/Omim/dispmim?179616.

100. Online Mendelian Inheritance in Man, OMIM. McKusick-Nathans Institute for Genetic Medicine, Johns Hopkins University (Baltimore, MD), and National Center for Biotechnology Information, National Library of Medicine (Bethesda, MD), 2003. Available at: http://www3.ncbi.nlm.nih.gov/htbin-post/Omim/disp$\operatorname{mim} ? 602450$.

101. Chapel H. Geha R, Rosen F. Primary immunodeficiency diseases: an update. Clin Exp Immunol 2003;132:9-15. 